\title{
A SITUAÇÃO MINORITÁRIA DOS SURDOS E SUA VULNERABILIDADE LINGUÍSTICA NA EDUCAÇÃO
}

\author{
THE DEAF PEOPLE MINORITY SITUATION AND THEIR LINGUISTIC \\ VULNERABILITY ON EDUCATION
}

\author{
Pedro Henrique Witchs ${ }^{1, *}$
}

\begin{abstract}
RESUMO: O objetivo deste artigo é discutir a surdez como uma experiência que constitui sujeitos de uma minoria linguística nos limites do Estado nacional. Para tanto, sob a perspectiva foucaultiana da governamentalidade, explora-se um conjunto de políticas que regulamentam o comportamento linguístico das pessoas surdas no campo educacional. A partir disso, é possível assumir que as condições sociais e políticas dispostas a essa população operacionalizam a manutenção de uma vulnerabilidade linguística, portanto também social, que inviabiliza direitos dignos da vida em sociedade.
\end{abstract}

Palavras-chave: Surdos. Governamentalidade. Minoria linguística. Vulnerabilidade. Políticas linguísticas.

\begin{abstract}
This article aims to discuss deafness as an experience that constitutes subjects of a linguistic minority within the limits of the national State. For this purpose, under the Foucaultian perspective of governmentality, it is explored a set of policies that regulate the linguistic behavior of deaf people in the educational field. From this, it is possible to assume that the social and political conditions available to this population operationalize the maintenance of a linguistic and, consequently, also social vulnerability, which prevents the dignified rights of life in society.
\end{abstract}

Keywords: Deaf people. Governmentality. Linguistic minority. Vulnerability. Language policies.

\footnotetext{
1.Universidade Federal do Espírito Santo - Departamento de Línguas e Letras; Programa de Pós-Graduação em Linguística - Vitória (ES), Brasil.

*Autor correspondente: pedro.witchs@ufes.br

Número temático organizado por: Adriana da Silva Thoma (I.M.) e Betina Hillesheim
} 


\section{Introdução}

Ser minoria não é uma questão numérica. As minorias existem sempre em relação a uma posição hegemônica dada. Por isso, prefiro falar em línguas em situação minoritária ou, simplesmente, línguas minorizadas, para me referir aos idiomas que não dispõem dos equipamentos a serviço das línguas hegemônicas; ou bem às situações em que uma língua se encontra à margem das estruturas de poder (LAGARES, 2018, p. 121).

De acordo com Lagares (2018), é no interior da estrutura política do Estado nacional que se exerce a hegemonia linguística. Essa compreensão está relacionada com a complexa discussão sobre a necessidade de políticas específicas para pessoas surdas. Se, por um lado, em virtude do impedimento auditivo, essas pessoas são consideradas deficientes sensoriais, por outro, graças às peculiaridades linguísticas, são consideradas culturalmente diferentes. Se, por um lado, a diferença linguística coloca os surdos no mesmo patamar das discussões étnicas, por outro, torna-se difícil conceber esse lugar aos surdos cuja origem genealógica não esteja associada à surdez. Desse modo, as pessoas surdas se inscrevem, na história, como exceções de diferentes categorias que tradicionalmente os classificariam como um determinado tipo de pessoa. Opto por analisar as condições sociais dos surdos desde um a priori histórico e a partir da correlação de três eixos propostos por Foucault (2010): a formação de saberes sobre os sujeitos; a normatividade de seus comportamentos; e a constituição de seus modos de ser.

Neste artigo, meu objetivo é discutir a surdez como uma experiência que constitui sujeitos de uma minoria linguística nos limites do Estado nacional. Para tanto, metodologicamente, destaco o eixo do poder. Isto é, coloco em evidência estratégias e práticas de exercício do poder visíveis em políticas que instauram a normatividade de comportamentos do sujeito surdo. Nesse sentido, proponho explorar um conjunto de políticas linguísticas que, historicamente, regulamentam os usos que os surdos fazem das línguas. Essas políticas estão diluídas, principalmente, em documentos que estruturam e orientam a educação de surdos na Contemporaneidade.

Para tanto, o texto está organizado como segue: após esta breve introdução, apresento uma historicização da experiência da surdez, com destaque para as práticas que a constituem como um risco perante o Estado, sob a perspectiva da governamentalidade, aqui entendida como uma grade de inteligibilidade (MORGENSTERN, 2019). Na sequência, caracterizo o processo de minorização linguística sofrido pelas línguas de sinais, e articulo essa discussão ao tema da vulnerabilidade social. Em seguida, exploro as políticas linguísticas evidenciadas no contexto brasileiro. Por fim, argumento que as condições sociais e políticas colocam em operação a manutenção da vulnerabilidade das pessoas surdas, de modo a dificultar aspectos da vida em sociedade para essa população.

\section{A Governamentalidade na Constituição da Surdez como Risco}

Para que a discussão sobre a ideia de risco atribuída à surdez possa ser desenvolvida, entendo ser antes necessário explicitar a noção de governamentalidade. Ao longo da obra foucaultiana, a compreensão sobre as relações de poder é refinada com a inclusão do termo conduta, que, para Foucault, é "a atividade que consiste em conduzir, a condução, [...] mas é também a maneira como uma pessoa se conduz, a maneira como se deixa conduzir, a maneira como é conduzida" (2008, p. 255). Esse termo contribuiu para um dos sentidos do conceito de governamento, que, de maneira resumida, compreende a condução das condutas de indivíduos e grupos. $\mathrm{O}$ governamento, entretanto, não pode ser entendido como uma prática restrita ao Estado. Contudo, é no Estado que o governamento, seja ele de qualquer modalidade, encontra os limites da sua finalidade. 
Ao analisar a emergência da racionalidade governamental, Foucault (2008) observa que ela corresponde ao surgimento do Estado moderno, assim como também do saber estatístico que se volta ao conhecimento da população. Nesse sentido, o autor passa a assumir que a governamentalidade, entre outras definições, pode ser entendida como "o processo, ou antes, o resultado do processo pelo qual o Estado de justiça da Idade Média, que nos séculos XV e XVI se tornou o Estado administrativo, viu-se pouco a pouco 'governamentalizado"' (FOUCAULT, 2008, p. 144). Na esteira do entendimento desse conceito, metodologicamente, entendo a governamentalidade como proposto por Morgenstern (2019). De acordo com a autora, esse conceito "sintetiza e amarra as ferramentas operatórias e funciona como uma grade de inteligibilidade que permite pensar as práticas sociais, educativas e corretivas" (MORGENSTERN, 2019, p. 200).

Pesquisadores da Educação que estudam a temática da governamentalidade têm entendido que a emergência da educação pública está relacionada com o bom governamento da população. Isso significa compreender que, conforme Nogueira-Ramírez, "com o aparecimento dessa nova forma de governo, dessa razão governamental, [...] apareceu a instrução como a chave do novo poder” (2011, p. 111). A educação de surdos, por sua vez, não está fora dessa racionalidade, uma vez que, em sua origem, ela é uma preocupação de governo. Nesse sentido, importa entender que a emergência da educação de surdos está diretamente relacionada à necessidade de conduzir as condutas dos surdos para a vida em sociedade. Tenho assumido que a articulação entre impedimento auditivo e diferença linguística operou - e opera até hoje - para que essa necessidade se expresse na importância de tornar a educação de surdos, primordialmente, uma educação linguística.

Essa forma de conceber a educação de surdos está ancorada nas práticas e discussões sobre o ensino de surdos que, no decorrer de sua história, concentram-se no objetivo de desenvolver, em crianças surdas, a capacidade de usar as línguas falada e escrita. Assim, na Europa do século XVIII, as discussões sobre a existência e a função da linguagem tomam a surdez como foco de suas análises. É por volta desse período que Davis (1995) identifica o aumento de publicações sobre os surdos, sobre formas de comunicação sinalizadas e sobre as técnicas de ensino da fala e da escrita voltadas a esses sujeitos. Isso também fica evidente, no final do século XIX, com a realização de uma série de congressos, pela Europa e a América do Norte, voltados à situação dos surdos. O mais famoso deles, o Congresso Internacional de Educação de Surdos, comumente chamado Congresso de Milão e realizado em 1880, demarca a tomada de decisão em relação à exclusão de métodos de ensino que exigissem o uso de línguas de sinais e outros recursos gestuais associados a elas, como o alfabeto manual.

As discussões que demarcam o Congresso de Milão, entretanto, são centrais em toda a sequência de eventos, antes e depois dele. Após esse congresso, segundo Rodrigues, Vieira-Machado e Vieira (2019), foram realizados pelo menos mais cinco outros. Dentre eles, o Congresso Internacional para Estudo das Questões de Educação e de Assistência de Surdos-Mudos, realizado em Paris no ano de 1900, merece destaque, "porque é o evento que, após 20 anos de Milão e tendo a participação tanto de ouvintes quanto de surdos, se debruçará sobre a questão da assistência, sugerindo um rompimento dessa prática para uma implementação de uma educação de surdos" (RODRIGUES; VIEIRA-MACHADO; VIEIRA, 2019).

No caso do Brasil, a tese de doutoramento defendida por Bacellar ([1926]2013) na Faculdade de Medicina de São Paulo permite observar o tratamento dado à surdez no início do século XX. Em seu trabalho, o médico discorre sobre a etiologia da surdez, bem como a anatomia e a patologia dos órgãos da audição e da fala. Ele também apresenta, além de políticas de prevenção da surdez, um relatório detalhado com dados estatísticos sobre a ocorrência de surdos em todo o território nacional. Entre suas conclusões, Bacellar (2013, p. 134) reafirma a necessidade de surdos se tornarem cidadãos úteis e capazes de suprir a própria subsistência, sem causar ônus à sociedade. Essa tese, assim como o tópico central do Congresso de Paris, em 1900, reforça o processo de governamentalização que sustenta as práticas educacionais na Modernidade ocidental, sobretudo quando se observa a importância dada aos números em relação aos surdos. 
Na compreensão de que a estatística opera como uma tecnologia para governar, Traversini e Bello (2009) explicam como decisões administrativas para modelar características de uma determinada população são tomadas com base em números, medidas, índices e taxas que dizem sobre a vida e a morte das pessoas. A estatística, portanto, "é utilizada por governos das diferentes esferas públicas, para situar comunidades com altos índices de analfabetismo, por exemplo, como sendo de risco social" (TRAVERSINI; BELLO, 2009, p. 143). Ainda segundo os autores, a prática da gestão do risco, uma forma de governamento que depende dos dados estatísticos, atua nas formas de conduzir a conduta de uma determinada comunidade para fazê-la sair de sua condição.

Tomarei o exemplo do analfabetismo usado pelos autores, porque ele está diretamente relacionado à necessidade de desenvolver a fala e a escrita em surdos. Isso significa compreender que, na racionalidade que responsabiliza o indivíduo pelo seu destino, de modo que seja diminuída sua dependência do Estado, a educação de surdos se configura como um empreendimento de gestão de um risco calculado sobre a surdez. Sob a lógica dos saberes produzidos em prol do governamento - nesse caso, não somente da estatística, mas também da medicina -, o impedimento auditivo é também um impedimento para um desenvolvimento linguístico comum ao território nacional, o que significa também o possível impedimento à leitura e à escrita.

Até aqui, caracterizei o contexto em que a surdez emerge como um risco que precisa ser gerido para fins de governamento da população surda por parte do Estado nacional. Na sequência, articulo essa discussão ao tema da vulnerabilidade social associado à minorização linguística condicionada aos surdos que têm alguma língua de sinais como primeira língua.

\section{Língua de Sinais Minorizada e Vulnerabilidade Social}

Os primórdios da Idade Moderna compreendem um período que Burke (2010) chama de a era da descoberta da língua. O historiador observou que, nesse período, é possível mapear uma série de atitudes em relação às línguas ou de mudanças de atitudes em relação a elas por toda a Europa. Dentre os inúmeros casos explicados pelo autor, destacam-se as relações entre língua e política que permitiram a expansão dos vernáculos como línguas amplamente adotadas nos domínios jurídicos e administrativos. É importante, contudo, entender que, a ascensão dessas línguas, de acordo com o autor, ocorreu em detrimento de outras: "o francês à custa da língua occitana, o inglês à custa do galês, o espanhol à custa do catalão, o alemão à custa do tcheco, o polonês à custa da língua rutena, o dinamarquês à custa do norueguês, e assim por diante" (BURKE, 2010, p. 91). Nesse clima da história das exclusões linguísticas que contribuíram para a consolidação das unidades nacionais, considero apropriado localizar as línguas de sinais.

Ainda que, epistemologicamente, não pudessem ser entendidas como equivalentes às línguas expressadas oralmente e compreendidas auditivamente, as línguas de sinais usadas por surdos aparecem em registros históricos desde a Antiguidade. Isso implica deduzir que os surdos, como grupo linguístico, possuem uma espessura histórica ainda pouco conhecida. A história dos surdos, entretanto, começou a ser mais registrada na medida em que os princípios humanísticos da Modernidade, na esteira da governamentalização do Estado, possibilitaram as condições para que esses sujeitos ingressassem na vida em sociedade. Esse ingresso, entretanto, custaria o abandono de um comportamento linguístico tido como abjeto se considerarmos que, como mostrou Elias (2011), a demonstração explícita das emoções e os gestos de movimento acelerado que tendem a seguir esse comportamento - duas características comuns na comunicação em língua de sinais compunham aquilo que precisaria ser rejeitado durante o processo civilizador do homem moderno.

Para se tornar indivíduos governáveis e autossustentáveis, os surdos precisariam ser alfabetizados na língua oficial e, aqueles que obtivessem sucesso em sua escolarização também poderiam ser capazes de falar e ler lábios. Se, antes de esse processo ter início, as línguas de sinais permaneciam vivas em pequenos 
grupos consanguíneos ou entre surdos isolados que, por acaso, unissem-se, a institucionalização da educação de surdos se tornou uma significativa plataforma de consolidação de comunidades surdas nacionais. A partir dos primeiros empreendimentos escolares voltados a surdos, portanto, observa-se o fortalecimento desse grupo como uma unidade linguística e social.

Assim, a língua de sinais se tornou o símbolo sob o qual a união entre surdos era possível. Em defesa do direito de utilizá-la como sua própria língua diante da intensificação das ideias oralistas em seu processo educacional, os surdos iniciaram um movimento político em prol da língua de sinais ainda no século XIX. A partir de 1834, segundo Benvenuto e Séguillon (2016), os surdos franceses passaram a promover banquetes não apenas como pretexto para reforçarem seus laços sociais, como também para camuflar os protestos proibidos durante a monarquia. Esses banquetes, de acordo com os autores, "se constituíram no espaço que fez emergir a 'nação surda', para usar aqui o vocabulário daquela época”' (BENVENUTO; SÉGUILLON, 2016, p. 67).

A percepção de que os surdos constituem um grupo minoritário, entretanto, vai aparecer mais tarde, na segunda metade do século XX. É nesse mesmo período que se vê a proliferação da reafirmação de identidades culturais que escapavam às tentativas de homogeneização da população sob a égide da nacionalidade. Após estudos publicados no campo da Linguística na década de 1960, a compreensão de que as línguas de sinais constituíam línguas verdadeiras em seu sentido linguístico pleno abriu margens para se perceber as tensões do contato entre línguas vividas pelos surdos. Com base na experiência de surdos estadunidenses e franceses, Mottez (2017) reforça a percepção sobre a minoria linguística dos surdos na década de 1970. Para o sociólogo, esses sujeitos apresentam alguns critérios que os permitem ser identificados dessa forma tais como: i) ter uma língua incompreendida pela maioria; ii) ser bilíngues, mesmo que com pouco domínio da segunda língua; e iii) receber desconfiança e certo desprezo pela maioria. De acordo com o autor, a situação dos surdos pode ser transformada com uma mudança política em relação a eles e às línguas de sinais.

Entendendo que a situação minoritária resulta de um processo histórico que pressiona comunidades linguísticas ao bilinguismo unilateral (ARACIL, 1982 apud LAGARES, 2018, p. 136), é possível dimensionar a fragilidade linguístico-social a qual os surdos estão expostos. O bilinguismo tão aclamado para educação de surdos, na lógica da governamentalidade, pode ser entendido como assume Vieira-Machado (2010): uma estratégia de sobrevivência. Conforme a autora, saber ler e escrever na língua majoritária é mais do que um fator de inclusão social para o surdo, "é a prova constante de que esse sujeito se coloca, para os ouvintes, como 'pessoa capaz" (VIEIRA-MACHADO, 2010, p. 60). Se as formas de acessar o meio social exigem dos surdos esse movimento unilateralmente bilíngue, então é possível assumir a situação de vulnerabilidade à qual eles estão expostos.

No caso das pessoas surdas entendidas como uma minoria linguística, Karnopp (2017) argumenta que é possível considerá-las autônomas e capazes de proteger seus próprios interesses. Entretanto, a autora reforça que as relações com essa população em específico, consideradas as implicações éticas, "requerem cuidado especial na mediação linguística e cultural" (KARNOPP, 2017, p. 223).

Relativamente diferente da discussão no campo da ética, o meu foco, neste artigo, está na noção de vulnerabilidade social, noção essa que está relacionada com a maneira pela qual se acessam "os serviços públicos para assegurar os direitos sociais, tais como, educação, trabalho, saúde, moradia, participação, dentre outros, [...] buscando qualidade de vida e bem-estar social" (MUSIAL; MARCOLINO-GALLI, 2019, p. 296). Observo que, apesar do fortalecimento das políticas de inclusão no fim do século XX, são mantidas as dificuldades de acesso, por parte dos surdos, nos diferentes setores da sociedade, sobretudo porque a minorização das línguas de sinais tem efeitos concretos na participação desses sujeitos na dinâmica social.

Desde a problemática sobre a língua que deverá ser inicialmente adquirida por um bebê surdo, passando pelo debate sobre os modelos linguístico-pedagógicos a partir dos quais as crianças surdas são educadas, até às dificuldades de contarem com interpretação ou tradução para línguas de sinais nos serviços 
públicos, a fragilidade da cidadania exercida pelos surdos está estreitamente associada a uma condição que envolve as línguas. Nesse sentido, argumento que a vulnerabilidade social resultante do processo de significação da surdez como risco é, primordialmente, uma vulnerabilidade linguística. Na seção a seguir, evidencio a manutenção da vulnerabilidade linguística em surdos a partir de um conjunto de políticas linguísticas para surdos no contexto brasileiro.

\section{Políticas Linguísticas de Educação de Surdos}

Ao apontar para o aumento de investimentos que visam à normalização da população surda na última década, Thoma (2016) observou que a proliferação discursiva dos direitos humanos usa argumentos que tanto favorecem o uso e a difusão das línguas de sinais quanto impulsionam tecnologias de correção, como, por exemplo, implantes cocleares, que desfavorecem essas línguas. Nesse sentido, a população surda, segundo a autora, é "conduzida para que seja participativa e produtiva [...], com vistas a fazer com que os sujeitos surdos possam ingressar e permanecer na escola e no mercado de trabalho, sendo capazes de produzir e consumir, não se tornando dependentes do Estado" (THOMA, 2016, p. 769).

Assim, para garantir a segurança desse grupo e diminuir os riscos sobre ele, a governamentalidade coloca em operação estratégias que podem ser evidenciadas no conjunto de políticas voltadas aos surdos. Na esteira dos direitos humanos, em 1996, é convencionada a Declaração Universal dos Direitos Linguísticos. No que se refere aos direitos linguísticos dos surdos, esse documento soma esforços com aqueles destinados aos direitos das pessoas com deficiência, como a Declaração de Salamanca, de 1994, que trata de princípios, políticas e práticas da educação especial; e a Convenção Internacional sobre os Direitos das Pessoas com Deficiência, de 2006. É nesses documentos que os movimentos surdos ao redor do mundo, convergidos na World Federation of the Deaf, encontram ressonâncias para sua luta linguística e passam a conquistar, em diferentes países, o reconhecimento legal de suas línguas de sinais. Portanto, entre 1995 e 2016, é possível observar cerca de 45 países, distribuídos entre África, Américas, Ásia, Europa e Oceania, que reconheceram legalmente pelo menos uma língua de sinais nacional (HLIBOK, 2018).

É válido salientar que o reconhecimento de uma língua de sinais pode ser atrelado à regulamentação do uso e do ensino dessa língua, o que instaura políticas linguísticas para surdos. Tenho observado que a maioria das políticas linguísticas para surdos, no cenário internacional, está diluída em políticas educacionais inclusivas. Isso implica compreender que tais políticas operam no âmbito da condução das condutas desses sujeitos, instaurando uma regularidade para os seus comportamentos e estabelecendo condições para a manutenção de uma situação minoritária. Para sustentar minha argumentação, explicito a seguir o caso brasileiro.

A língua brasileira de sinais (Libras) foi legalmente reconhecida, em nível federal, no ano de 2002. Antes disso, havia casos de reconhecimento nas esferas estaduais e municipais. Contudo, esse reconhecimento, oficializado pela conhecida Lei de Libras, explicitamente impede que a modalidade escrita da língua portuguesa seja substituída pela língua de sinais. Aqui, é possível ver em operação o primeiro mecanismo da governamentalidade que alimenta a manutenção da vulnerabilidade linguística nos surdos. Ele condiciona o bilinguismo unilateral imposto a essa parcela da população e gera efeitos diretos, não apenas nas práticas educacionais voltadas aos surdos, como também nas questões de acesso e permanência desses sujeitos nas instituições do Estado.

Essa situação sofre modulações em 2005, com o Decreto Federal n. 5.626. A partir dele, são instauradas algumas normativas que incumbem o Estado de garantir a acessibilidade das pessoas surdas mediante a interpretação e a tradução para língua de sinais. Esse documento, segundo Lodi (2013, p. 53), enfatiza "a necessidade de implantação da educação bilíngue para esses alunos e, a fim de que essa proposta seja efetivada, estabelece como deve ser a formação dos profissionais para atuarem junto a esses estudantes". Assim, observa-se a difusão da Libras como 
disciplina obrigatória nos cursos de formação de professores dos níveis Superior e Médio, bem como nos cursos de graduação em Educação Especial e Fonoaudiologia. A partir desse decreto, também passa a haver as condições para o surgimento dos cursos de bacharelado e licenciatura em Letras com habilitação em Libras, de modo a promover a formação superior tanto de professores quanto de intérpretes e tradutores dessa língua.

$\mathrm{Na}$ intenção de rever alguns postulados incluídos no decreto de 2005, no ano de 2008, é instaurada a Política Nacional de Educação Especial na Perspectiva da Educação Inclusiva. Ao fazer uma análise comparativa entre o decreto e a política, Lodi (2013) argumenta que a educação bilíngue, no texto de 2008, é reduzida à presença de duas línguas na escola e que o português é mantido como a língua hegemônica nos processos educacionais. De acordo com a autora, "o discurso pelo reconhecimento da diversidade presente na política instaura resistências que inviabilizam o estabelecimento de diálogos com as comunidades surdas brasileiras" (LODI, 2013, p. 61). Observo, portanto, não um avanço das discussões a partir da política, mas uma multiplicação de compreensões sobre as formas de se educar surdos e, consequentemente, de conduzir seus comportamentos linguísticos. Apesar desse conjunto de políticas linguísticas incorporar a ideia de que a Libras possa ser a primeira língua de crianças surdas e a língua de instrução em seu processo de escolarização, noto que a língua de sinais tem figurado ora como uma ferramenta pedagógica para o ensino das crianças surdas, ora como um instrumento de inclusão, por permitir sua acessibilidade. Entretanto, nas políticas linguísticas para surdos, a língua de sinais pouco aparece como elemento linguístico-cultural a partir do qual é possível exercer cidadania e livre expressão.

Isso implica compreender que os surdos, caso desejem entender e se fazer entender, em língua de sinais, em qualquer situação social para além de sua comunidade, dependem do bom funcionamento dos mecanismos que resguardam a sua inclusão na sociedade. Ao analisar essas condições no contexto estadual de Santa Catarina, Quadros (2006) observou que as propostas governamentais apresentavam incompatibilidade com os anseios dos surdos. Naquele período, a autora já indicava que esse era "o grande entrave do processo inclusivo dos surdos na educação" (QUADROS, 2006, p. 157). Isto é, eles dependem da existência de um ambiente linguístico que seja propício ao desenvolvimento da aquisição da linguagem em seus primeiros anos de vida, bem como para o desenvolvimento da aprendizagem de sua primeira língua durante os seus anos de escolarização. Dependem de materiais didáticos ou de entretenimento disponíveis na língua de sinais, bem como da disponibilidade orçamentária dos órgãos públicos para a contratação de intérpretes e tradutores de língua de sinais que possam trabalhar em condições dignas às funções laborais inerentes a esse tipo de atividade.

Entretanto, em dezembro de 2019, o Decreto Federal n. 10.185 passou a extinguir cargos efetivos vagos e que vierem a vagar dos quadros de pessoal da administração pública federal, bem como a vedar a abertura de concurso público e o provimento de vagas adicionais para alguns desses cargos. Consta, da lista de cargos cuja abertura de concurso público é vetada pelo decreto, o cargo de tradutor e intérprete de linguagem de sinais do Plano de Carreiras dos Cargos Técnico-Administrativos em Educação. Em decorrência disso, com o crescente ingresso de surdos nas instituições públicas de ensino, o que se vê agora são as dificuldades enfrentadas por equipes de tradução e de interpretação de Libras e português diante da quantidade de demandas que precisam atender, o que implica diretamente a qualidade da educação de surdos em todos os níveis. Como uma alternativa a esse e outros problemas decorrentes da precarização do Estado, em 2019, também foi criado o Programa Nacional de Incentivo ao Voluntariado, o que tornou oportuna a possibilidade de contratação de intérpretes de língua de sinais voluntários. Essa questão, por sua vez, abre precedentes para que as conquistas trabalhistas da categoria de tradutores e intérpretes de língua de sinais sofram sequelas.

Esses e muitos outros elementos sobre os quais não me detive neste artigo reforçam a manutenção do que venho entendendo ser a vulnerabilidade linguística dos surdos. Apesar da surdez ter constituído um risco a ser gerido perante a governamentalização do Estado moderno, reitero que as tentativas de agir sobre 
a seguridade da parcela surda da população, apesar de apresentarem uma história densa, até então, não garantiram condições para o esmaecimento da vulnerabilidade linguística, portanto social, à qual os surdos estão submetidos na Contemporaneidade.

\section{Considerações Finais}

As políticas linguísticas de educação de surdos, para Thoma (2016), são paradoxais e ambíguas. Essa pesquisadora, que dedicou sua vida acadêmica e profissional às políticas educacionais para surdos, evidenciou que elas, "de forma concomitante, festejam a diferença surda e investem na correção/normalização dos indivíduos com surdez" (THOMA, 2016, p. 770). Como tencionei mostrar neste artigo, adiciono à análise de Thoma (2006) a compreensão de que as políticas linguísticas de educação de surdos operam, sob a lógica da governamentalidade, na manutenção da vulnerabilidade linguística desses sujeitos.

Nesse sentido, observo que, a partir dessa manutenção, com fins de gerir o risco da surdez e conferir seguridade à população, as políticas linguísticas de educação de surdos servem como uma tecnologia de governo que minam a nação surda imaginada no século XIX. Na medida em que possibilitam recursos de regulação do comportamento dos surdos, sobretudo do comportamento linguístico deles, elas proporcionam as condições para torná-los sujeitos do Estado-nação.

Entendo que tais políticas constituem elementos necessários para a formação da cidadania dos surdos. Entretanto, assumo que, para esse fim, elas não têm sido suficientes, uma vez que não refletem a mudança de postura que se espera da sociedade em relação a esses sujeitos. Assim, espero que a discussão que articulei neste artigo fomente o debate social necessário tanto em círculos acadêmicos nas áreas da Educação e da Linguística Aplicada quanto nas mobilizações políticas das comunidades surdas. Espero, também, que esse debate alcance a gestão pública da educação dos surdos.

\section{REFERÊNCIAS}

BACELLAR, A. (1926). A surdo mudez no Brasil (cadeira de hygiene). Rio de Janeiro: INES, 2013. (Série Histórica. v. 6.)

BENVENUTO, A.; SÉGUILLON, D. Primeiros banquetes dos surdos-mudos no surgimento do esporte silencioso 1834-1924: por uma história política das mobilizações coletivas dos surdos. Moara, Belém, n. 45, p. 60-78, 2016. https://doi.org/10.18542/moara.v1i45.3707

BURKE, P. Linguagens e comunidades nos primórdios da Europa Moderna. São Paulo: Editora UNESP, 2010.

DAVIS, L. Enforcing normalcy: disability, deafness, and the body. London/New York: Verso, 1995.

ELIAS, N. O processo civilizador. 2. ed. Rio de Janeiro: Zahar, 2011. (Volume 1: Uma História dos Costumes.)

FOUCAULT, M. Segurança, território, população: curso dado no Collège de France (1977-1978). São Paulo: Martins Fontes, 2008.

FOUCAULT, M. O governo de si e dos outros. Curso no Collège de France (1982-1983). São Paulo: Martins Fontes, 2010. 
HLIBOK, T. H. Language policy in the context of sign languages and deaf community activism. Llengua, Societat i Comuunicació, Barcelona, n. 16, p. 54-62, 2018. https://doi.org/10.1344/LSC-2018.16.7

KARNOPP, L. B. Aspectos éticos em pesquisas envolvendo surdos: protagonismo ou vulnerabilidade. In: SANTOS, L. H. S.; KARNOPP, L. B. (orgs.). Ética e pesquisa em educação: questões e proposições às ciências humanas e sociais. Porto Alegre: Editora da UFRGS, 2017. p. 209-225.

LAGARES, X. C. Qual política linguística?: desafios glotopolíticos contemporâneos. São Paulo: Parábola, 2018.

LODI, A. C. B. Educação bilíngue para surdos e inclusão segundo a Política Nacional de Educação Especial e o Decreto n. 5.626/05. Educação e Pesquisa, São Paulo, v. 39, n. 1, p. 49-63, 2013. https://doi.org/10.1590/ S1517-97022013000100004

MORGENSTERN, J. M. A governamentalidade como grade de inteligibilidade no campo da teorização. In: LOPES, M. C.; MORGENSTERN, J. M. (orgs.). Inclusão e subjetivação: ferramentas teórico-metodológicas. Curitiba: Appris, 2019. p. 193-205.

MOTTEZ, B. Os surdos como minoria linguística. Revista Espaço, Rio de Janeiro, n. 48, p. 21-24, 2017. https://doi.org/10.20395/re.v0i48.395

MUSIAL, D. C.; MARCOLINO-GALLI, J. F. Vulnerabilidade e risco: apontamentos teóricos e aplicabilidade na Política Nacional de Assistência Social. O Social em Questão, Rio de Janeiro, n. 44, p. 291-306, 2019.

NOGUERA-RAMÍREZ, C. E. Pedagogia e governamentalidade ou da Modernidade como uma sociedade educativa. Belo Horizonte: Autêntica, 2011.

QUADROS, R. M. Políticas linguísticas e educação de surdos em Santa Catarina: espaço de negociações. Caderno Cedes, Campinas, v. 26, n. 69, p. 141-161, 2006. https://doi.org/10.1590/S0101-32622006000200003

RODRIGUES, J. R.; VIEIRA-MACHADO, L. M. C.; VIEIRA, E. T. B. Congresso de Paris (1900): a seção de surdos e sua atualidade em relação à educação de surdos. Revista Brasileira de História da Educação, Maringá, v. 20, n. 1, p. e095, 2019. https://doi.org/10.4025/rbhe.v20.2020.e095

THOMA, A. S. Educação bilíngue nas políticas educacionais e linguísticas para surdos: discursos e estratégias de governamento. Educação \& Realidade, Porto Alegre, v. 41, n. 3, p. 755-775, 2016. https://doi. org/10.1590/2175-623661087

TRAVERSINI, C. S.; BELLO, S. E. L. O numerável, o mensurável e o auditável: estatística como tecnologia para governar. Educação \& Realidade, Porto Alegre, v. 34, n. 2, p. 135-152, 2009.

VIEIRA-MACHADO, L. M. C. Ser bilíngue: estratégias de sobrevivência dos sujeitos surdos na sociedade contemporânea. In: VIEIRA-MACHADO, L. M. C.; LOPES, M. C. (orgs.). Educação de surdos: políticas, língua de sinais, comunidade e cultura surda. Santa Cruz do Sul: EDUNISC, 2010. p. 48-67.

Recebido: 01 Out. 2019

Aceito: 10 Set. 2020

Editoras Associadas:

Daniela Dias dos Anjos e Ana Luiza Bustamante Smolka 